\title{
O empreendedorismo acadêmico no contexto da interação universidade - empresa - governo
}

\author{
Academic enterprising in the university interactions context - industry - government
}

\author{
Ana Sílvia Rocha Ipiranga ${ }^{1}$ \\ Ana Augusta Ferreira de Freitas ${ }^{2}$ \\ Thiago Alves Paiva ${ }^{3}$
}

\begin{abstract}
Resumo
No contexto da cooperação entre universidade, empresa e governo sobressaem-se os conceitos complementares de "universidade empreendedora" e "empreendedorismo acadêmico", nos quais uma instituição acadêmica vai além da formação, desempenhando um papel no Sistema de Inovação e no desenvolvimento do país. Considerando essa discussão, este estudo tem como objetivo abordar a questão da capacitação da universidade para promover a cooperação, tendo como base as seguintes questões de pesquisa: Como ocorre a cooperação da universidade com as empresas e o governo e desses com a universidade? Quais as barreiras e vantagens para os entes participantes? Que contratos e arranjos são articulados para a concretização dessa interação? A metodologia de natureza qualitativa faz uso do caso Parque de Desenvolvimento Tecnológico (PADETEC) ligado a uma universidade federal, enquanto instituição situada na fronteira dessas relações. A análise dos dados baseou-se na técnica da análise temática que se insere no conjunto das técnicas da Análise de Conteúdo. A análise evidenciou que há atuação de uma universidade empreendedora, mas, sobretudo, o empreendedorismo acadêmico dá sinais de existência; porém, é preciso ainda percorrer um longo caminho para se consolidar estes conceitos e, em consequência, a complementaridade entre suas respectivas práticas.
\end{abstract}

Palavras-chaves: Empreendedorismo acadêmico; Tríplice Hélice; Sistemas de Inovação.

\begin{abstract}
In the context of cooperation between university, company and government, the complementary concepts of "enterprising university" and "academic enterprising" stand out. This occurs when an academic institution is going beyond the formation, playing a part in the System of Innovation and in the development of the country. Considering this discussion, the aim of this study is to approach the subject of training at the university to promote cooperation, based on the following research subjects: How does the cooperation of the university with companies and government and of these with the university occur? What are the barriers and advantages for those participating in these processes? What contracts and arrangements are articulated for the materialization of this interaction? The qualitative methodology makes use of the case of the Technological Development Park (PADETEC) linked to a federal university as an institution located on the border of these relationships. The analysis of the data was based on the thematic analysis technique that is inserted in the group of Content Analysis techniques. The analysis showed that there is evidence of an enterprising university and that, above all, there are signs of academic enterprising. However, there is a long way to go in order to consolidate these concepts and, therefore, before they can complement one another in their respective practices.
\end{abstract}

Keywords: Academic Enterprising, Triple Helix, Systems of Innovation.

\footnotetext{
Artigo submetido em dezembro de 2008 e aceito para publicação em fevereiro de 2010.

${ }_{1}^{1}$ Doutorado. Universidade Estadual do Ceará. Endereço: Av Paranjana, 1700 Campus do Itaperi - Fortaleza - CE. E-mail: ana.silvia@pq.cnpq.br

2 Doutorado em Eng. de Produção (UFSC), Professora titular, Membro do corpo permanente do Curso de Mestrado Acadêmico em Administração, Universidade Estadual do Ceará (UECE). Endereço: Campus do Itaperi, Av.Paranjana, 1700, Fortaleza-CE, 85-31019940. E-mail: freitas8@terra.com.br.

${ }^{3}$ Bacharel em Administração, Acadêmico de Direito e Pos-Graduando (Especialização) em Direito Tributário. Faculdade Cathedral de Boa Vista/RR. Endereço: Av. Luís Canuto Chaves, 293 - Caçari - CEP: 69.307-053 - Boa Vista - Roraima. E-mail: talvesp@gmail.com
} 


\section{Introdução}

As discussões sobre a cooperação universidade - empresas - governo têm se acirrado desde 1970, principalmente em decorrência do curto ciclo de vida das inovações. Os primórdios desses estudos ocorreram na Alemanha, no século XIX, chegando ao Reino Unido no início do século XX. Entretanto, as práticas concernentes a esse tipo de relacionamento adquirem uma personalidade mais definida nos Estados Unidos, a partir dos anos da década de 1980 (Cf. SCHMOCH, 1999; SBRAGIA, 2006; GARNICA; FERREIRAJÚNIOR; FONSECA, 2005).

Na América Latina, a realidade foi diferente. Ao basear seu desenvolvimento na importação da tecnologia, a universidade, através da criação de pró-reitorias de extensão, dedicou-se às tarefas mais de caráter assistencial e cultural e ao papel preponderante de formação de recursos humanos para a absorção de tecnologia estrangeira. No Brasil não foi diferente. Até a década de 1960, essa era a postura. Foi com o fim da política de substituição de importações nos anos de 1980 e a criação pelo governo de Políticas de Ciência e Tecnologia (C\&T) que os brasileiros passaram a despender mais atenção ao desenvolvimento tecnológico, atitude que passou a ser mais cobrada a partir de 1990 com a liberalização dos mercados. Naquele momento, os diversos setores da economia, ao admitirem a importância de se investir em inovação, pesquisa e desenvolvimento, perceberam a influência do conhecimento e das capacidades de diferentes atividades produtivas e áreas científicas, começando a ponderar, como um caminho possível, a aproximação com as universidades e institutos de pesquisa.

Para Sbragia (2006), no início havia uma desconfiança mútua, diferença de linguagem ou choque de cultura; resultado da falta de alinhamento de ideias e das imposições feitas pela academia. O incentivo ao estabelecimento desse vínculo foi se intensificando, sobretudo, através da implementação de políticas públicas governamentais, objetivando garantir a excelência em áreas temáticas consideradas estratégicas em função do seu potencial de contribuição para o crescimento da economia, melhoria da condição de vida da população, para competitividade das empresas, das regiões e das nações nos contextos local e global (SBRAGIA, 2006; LASTRES et al., 2005).

Ao reconhecer que a inovação é um processo cumulativo e interativo, vários foram os estudiosos que começaram a pensar a cooperação, em termos de Sistemas de Inovação, como um arranjo organizacional mais evoluído para captar as relações entre as universidades, governo e o sistema de produção - triple helix - e de compreender as distâncias de conhecimento e inovação entre as diferentes realidades (FREEMAN, 1987; LUNDVALL, 1985; SUTZ, 1997; ETZKOWITZ, 2004). No Brasil, durante os últimos 15 anos, tem ocorrido um posicionamento frente às demandas em prol do desenvolvimento e da inserção da economia brasileira no mercado mundial e, desta forma, tem-se trabalhado para estimular o Sistema de Inovação, o qual é entendido como um conjunto de arranjos institucionais, cuja composição é dada por diversas organizações de apoio, levando à proposição de programas de incentivo à parceria (VEDOVELLO; FIGUEIREDO, 2006; SBRAGIA, 2006).

Considera-se, portanto, que no contexto da cooperação entre empresas, universidades e governos, existe uma miríade de questões culturais, vantagens e barreiras, políticas governamentais, formas contratuais e arranjos que se baseiam em distintos objetivos e motivações das instituições envolvidas que precisam ser abordados. Essas discussões ressaltam ainda as questões da propriedade intelectual, das formas de licenciamento da tecnologia e dos registros de patentes no âmbito dos processos de transferência de tecnologia; isto porque, centros de pesquisa e universidades de excelência são pouco relevantes quando não ocorre a cooperação com o setor produtivo e governamental. Afinal, quem toma a iniciativa da aproximação? Lima e Fialho (2001) afirmam que, em regra, são as empresas que buscam as universidades para firmarem parcerias de cooperação. Porto (2002) evidencia que não existe doação gratuita de tecnologia nem assistencialismo por parte das universidades, mas uma transferência de competências resultante de novos investimentos. Sbragia (2006) realça o papel do governo através dos editais e programas de incentivo à parceria, nos quais a responsabilidade pela implementação recai em geral sobre a universidade. 
Corroborando com estas ideias, Etzkowitz (2004), Etzkowitz e Klofsten (2005) e Garnica, Ferreira-Júnior e Fonseca (2005) revisam os conceitos complementares de "universidade empreendedora" e de "empreendedorismo acadêmico". Estes conceitos destacam a existência de uma instituição acadêmica que não está só preocupada em formar profissionais qualificados para o mercado, mas também em desempenhar um papel no Sistema de Inovação e no desenvolvimento econômico, tecnológico e social do país, através da criação de estruturas complexas dentro da universidade para abrigar empresas de base tecnológica, e que tem na cooperação com empresários e com os pesquisadores da universidade sua base operacional.

Considerando as discussões supracitadas, este estudo tem como objetivo abordar a questão da capacitação da universidade para promover a cooperação, tendo como base os conceitos complementares de empreendedorismo acadêmico e universidade empreendedora. Assim, pretende-se responder as seguintes questões de pesquisa: (i) Como ocorre a cooperação da universidade com as empresas e governo e desses com a universidade? (ii) Quais as barreiras e vantagens para os entes participantes? (iii) Que contratos e arranjos são articulados para a concretização dessa interação?

A metodologia de natureza qualitativa faz uso do caso Parque de Desenvolvimento Tecnológico (PADETEC) da Universidade Federal do Ceará (UFC), enquanto instituição situada na fronteira dessas relações. Além da compilação de documentos, a coleta de dados teve por base roteiros de entrevista aplicados de forma individual com os gestores e um empresário do PADETEC. A análise dos dados baseou-se na técnica da análise temática que se insere no conjunto das técnicas da Análise de Conteúdo (BARDIN, 2004).

Este artigo está estruturado em seções, cobrindo os seguintes tópicos: revisão da literatura de suporte à investigação acerca dos principais aspectos sobre o tema da cooperação universidade, governo e empresa; percurso metodológico da pesquisa e a descrição do caso estudado. Na última seção são apresentadas algumas ideias conclusivas do trabalho.

\section{A cooperação universidade - governo - empresa e o empreendedorismo acadêmico}

A abordagem de tradição schumpeteriana dos Sistemas de Inovação deslocou o foco da produção para o tema da inovação, considerada como um processo interativo, em vez de linear, enfatizando o processo o qual empresas, em relação umas com as outras, são apoiadas por diferentes organizações privadas e governamentais inseridas em um contexto institucional mais amplo (FREEMAN, 1987; LUNDVALL, 1985; SUTZ, 1997).

Segundo Etzkowitz (2004) e Etzkowitz e Klofsten (2005), a triple helix, enquanto arranjo organizacional mais evoluído que postula a interação entre os três principais participantes do Sistema de Inovação (universidade, governo e empresa), foi o evento chave para a criação de uma "universidade empreendedora" e na promoção das condições em prol de uma sociedade baseada no conhecimento.

Interessante situar que a literatura disponível no contexto da universidade como agente do desenvolvimento faz uso de duas vertentes complementares de análise. Na primeira, enfoca-se a idéia da Universidade Empreendedora ou Universidade-Empresa no conceito de Marginson e Considine (2004); Etzkowitz (2004); Etzkowitz e Klofsten (2005), como um fenômeno que envolve as dimensões econômicas, acadêmicas e institucionais. Segundo estes autores, a Universidade Empreendedora distingue-se de outras no que diz respeito a três características básicas: (i) suporte a atividades empreendedoras; (ii) existência de mecanismos de interface, como os escritórios de transferência de tecnologia; e (iii) um número significativo de colaboradores capazes de formar firmas. Etzkowitz (2006) explica ainda que uma Universidade Empreendedora é capaz de transformar resultados de pesquisa, com potencial de comercialização, em empresas inovadoras, tendo as políticas de inovação como suporte e a possibilidade de impacto regional

O conceito de Universidade Empreendedora, desta forma, vincula-se estreitamente ao próprio conceito de empreendedorismo concebido por Schumpeter (1961), sendo que a Universidade passa a ser o lócus de criação e apoio a um sujeito apto a revolucionar um sistema de produção. As mudanças decorrentes de tais inovações seriam a força fundamental de desenvolvimento da economia dos países. Pesquisas sobre Universidade 
Empreendedora têm sido objeto de estudo de vários pesquisadores nos últimos anos e jornais internacionais (e.g. Journal of Technology Transfer, 2001; Management Science, 2002; Journal of Business Venture, 2004), os quais têm dedicado edições especiais sobre o tema. Entre as questões abordadas estão: (i) a importância das patentes como indicador efetivo de transferência de tecnologia (AGRAVAL; HENDERSON, 2002); (ii) as formas possíveis de comercialização de produtos desenvolvidos dentro da Universidade (BAINS, 2005); e (iii) a associação existente entre os gastos com pesquisa acadêmica e a geração de patentes (COUPE, 2003).

$\mathrm{Na}$ outra vertente, encontram-se os trabalhos que abordam a cooperação universidade - governo - empresa e sua relação com a inovação (e.g. FRITSCH; SCHWIRTEN, 1999), mais próximo do conceito de Empreendedorismo Acadêmico e que tem nas relações com empresários, agências de fomento governamentais e com os pesquisadores da universidade sua base operacional (GARNICA; FERREIRA-JÚNIOR; FONSECA, 2005).

Sobre este último aspecto, a cooperação universidade, governo e empresa é refletida nas palavras de Mancini e Lorenzo (2006), ao interpretarem Ploskin (1998), como algo mutuamente enriquecedor, o qual pode contribuir para que cada participante, dentro da sua realidade, avance na busca pela excelência. Sendo assim, a cooperação é um tipo de interação complexa e ativa para aqueles que estão diretamente envolvidos. Percebe-se que a cooperação é vista como algo em que há troca de interesses, similar a uma via de mão dupla onde carros trafegam indo e voltando (LIMA; FIALHO, 2001), pois tanto empresas como universidades buscam benefícios na parceria para promoção do desenvolvimento.

Segundo Sbragia (2006), o processo de cooperação universidade e empresa é dotado de distinção de valores, objetivos e cultura. Desta forma, as relações entre empresas e universidades são motivadas por diversos fatores, mas, ao mesmo tempo, são desestimuladas por outras tantas barreiras. Isso se deve ao fato de que ambas as organizações possuem naturezas distintas, com princípios e valores muitas vezes antagônicos, sendo que um dos principais conflitos apontados nesta relação está no direito de propriedade intelectual e, com base em Streharsky (1993), na questão da divulgação dos resultados das pesquisas. Contudo, já ficou evidenciado que a proteção dos resultados de pesquisa é imprescindível para que as empresas os transformem em inovação, alocando recursos adicionais para o seu desenvolvimento e aplicação no mercado (SBRAGIA, 2006). O Quadro 1 a seguir apresenta as principais barreiras identificadas na literatura à cooperação universidade empresa. 


\section{Quadro 1: Barreiras à cooperação universidade-empresa.}

\begin{tabular}{ll}
\hline \multicolumn{1}{c}{ UNIVERSIDADE } & \multicolumn{1}{c}{ EMPRESA } \\
\hline $\begin{array}{l}\text { Falta de regulamentações ou excessiva rigidez das } \\
\text { existentes; }\end{array}$ & $\begin{array}{l}\text { Escasso reconhecimento da tecnologia nos planos } \\
\text { empresariais; }\end{array}$ \\
$\begin{array}{l}\text { Não utilização de políticas mercadológicas aplicáveis } \\
\text { à oferta tecnológica universitária; }\end{array}$ & $\begin{array}{l}\text { Preferência por licenciar tecnologia ao invés de } \\
\text { desenvolvê-la; }\end{array}$ \\
$\begin{array}{l}\text { Descontinuidade de projetos em decorrência de } \\
\text { problemas políticos e/ou trabalhistas; }\end{array}$ & Visão imediatista dos negócios, que não inclui a \\
pesquisa; \\
$\begin{array}{ll}\text { de P\&Dentes não preparados para a realização de projetos com formação unidisciplinar; } & \text { Exigência de segredo e propriedade dos resultados da } \\
\text { Pesquisadores isolados da realidade, sem compreender } & \text { pesquisa; } \\
\text { as necessidades do setor produtivo; } & \text { Ambientes e estruturas organizacionais inadequadas para } \\
\text { Maior valorização da pesquisa básica do que da } & \text { a vinculação, além da falta de recursos financeiros para } \\
\text { pesquisa tecnológica aplicada e sua comercialização; } & \text { financiar projetos; } \\
\text { Diferenças culturais, de valores, atitudes e formas de } & \text { Pessoal desatualizado e com baixa motivação; } \\
\text { trabalho, dificultando a comunicação, além de } & \text { Desconhecimento da capacitação universitária; } \\
\text { diferentes concepções do tempo; } & \text { Aversão ao risco; } \\
\text { Visão do setor produtivo como somente interessado } & \text { Baixo compromisso com a participação nos projetos; } \\
\text { em seus benefícios próprios e não em retribuir à } & \text { Não percepção dos benefícios da vinculação; } \\
\text { universidade e à sociedade; } & \text { Visão da universidade como vivendo em um mundo } \\
\text { Lentidão nos trâmites burocráticos para aprovação de } & \text { irreal e distante; } \\
\text { convênios; } & \text { Suspeita e desconfiança nas capacidades da e nos } \\
\text { Falta de recursos financeiros; } & \text { resultados de suas atividades; } \\
\text { Carga horária elevada dos professores. } & \text { Sentimento de inferioridade com relação aos } \\
& \text { conhecimentos existentes na universidade; } \\
& \text { Imediatismo da indústria/empresa na busca por } \\
\text { resultados. }\end{array}$ \\
\hline
\end{tabular}

Fonte: Adaptado de Mancini e Lorenzo (2006); Garnica, Ferreira-Júnior e Fonseca (2005).

Se, por um lado, ainda existem resistências e barreiras à cooperação, por outro, são várias as motivações e fatores para buscá-la. Considerando o lado das universidades, alguns fatores podem ser evidenciados que alimentam o desejo pela cooperação. Entre estes fatores ressalta-se que as pesquisas científicas no Brasil estão hospedadas, principalmente, em instituições acadêmicas de caráter público e, desta forma, essas instituições recebem recursos, normalmente escassos, tão essenciais para o desenvolvimento do conhecimento. Com isso, a busca por novos recursos talvez seja um importante estímulo para que as universidades e os institutos de pesquisa almejem e participem do processo de cooperação com o mundo produtivo. Além da necessidade financeira, outros fatores contribuem para esta postura da universidade; pois a cooperação com as empresas permite uma aproximação com a realidade técnica, econômica e social, e sua incorporação nos currículos dos cursos, bem como a contribuição para a transformação tecnológica e social que se espera dos centros de pesquisa e das universidades (LIMA; FIALHO, 2001).

Para Fritsch e Schwirten (1999), a participação das universidades e centros de pesquisa nestas relações está geralmente vinculada à geração e ao desenvolvimento de novas ideias para empresas inovadoras. Geralmente, a cooperação é influenciada por diversos motivos. O principal deles, no caso das universidades, é adquirir inspirações práticas na formulação de projetos de pesquisa. A aproximação é também uma oportunidade para as universidades buscarem informações sobre como os resultados da pesquisa básica podem ser aplicáveis.

Alguns trabalhos apontam ainda a proximidade geográfica entre pesquisadores e empresas como um fator positivamente relacionado com a cooperação entre estes agentes. Outros trabalhos indicam a proximidade da universidade como influência positiva na existência de colaboração (e.g. MANSFIELD, 1995; AUDRETSCH; STEPHEN, 1996). No entanto, em regra, são as empresas que buscam as universidades para firmarem parcerias de cooperação, pois representam a oportunidade de encontrar na universidade respostas para seus problemas 
tecnológicos e consequentemente a melhoria da qualidade de produtos e processos, a sua modernização e aumento da competitividade (LIMA; FIALHO, 2001). Elas normalmente vêm motivadas a compartir recursos que muitas vezes são difíceis de serem percebidos ou adquiridos no mundo dos negócios em que estão inseridos, além da inviabilidade tanto técnica como econômica de atuarem sozinhas. Alguns desses recursos podem ser mão-de-obra qualificada, infraestrutura laboratorial e solução de problemas de ordem tecnológica (GARNICA; FERREIRA-JÚNIOR; FONSECA, 2005).

Muitas vantagens podem resultar da cooperação, tanto para as empresas como para as universidades e centros de pesquisa. As principais estão resumidas no Quadro 2 a seguir:

\section{Quadro 2: Fatores que levam à cooperação universidade-empresa.}

\begin{tabular}{|c|c|}
\hline UNIVERSIDADE & EMPRESA \\
\hline $\begin{array}{l}\text { Obtenção de novos recursos para pesquisa; } \\
\text { Aumento da relevância da pesquisa acadêmica, ao } \\
\text { lidar com necessidades da indústria ou da sociedade, e } \\
\text { o consequente impacto no ensino; } \\
\text { Possibilidade de emprego para estudantes graduados; } \\
\text { Possibilidade de futuros contratos de consultoria para } \\
\text { pesquisadores; } \\
\text { Possibilidade de futuros contratos de pesquisa. }\end{array}$ & $\begin{array}{l}\text { Acesso a recursos humanos qualificados; } \\
\text { "Janela ou antena tecnológica" (conhecer os avanços } \\
\text { em sua área de atuação); } \\
\text { Acesso precoce a resultados de pesquisa; } \\
\text { Solução de problemas específicos; } \\
\text { Acesso a laboratórios e instalações; } \\
\text { Formação de funcionários; } \\
\text { Melhoria de sua imagem e prestígio dentro da } \\
\text { sociedade; } \\
\text { Necessidade de aumentar sua competitividade; } \\
\text { Parte de sua estratégia tecnológica (padrão de } \\
\text { competição em seu setor); } \\
\text { Redução de riscos e custos de pesquisa. }\end{array}$ \\
\hline
\end{tabular}

Fonte: Sbragia (2006).

\section{A cooperação universidade - governo - empresa: etapas e arranjos para a transferência de tecnologia}

A relação entre universidade, governo e empresas pode acontecer através de diversas formas e arranjos, desde a consultoria individual de um professor até a organização de estruturas complexas como centros de pesquisa cooperativos, escritórios de transferência de tecnologia, incubadoras e parques tecnológicos (SBRAGIA, 2006). Faulkner e Senker (1994) registram que, na grande maioria das vezes, a cooperação com a universidade é baseada em contatos pessoais e não institucionais. Fritsch e Schwirten (1999), em um estudo conduzido em três regiões da Alemanha, ratificam este resultado ao demonstrarem que uma das principais formas de cooperação são os contatos informais com as empresas, estabelecidos a partir de motivações individuais de pesquisadores.

Projetos de cooperação entre universidade, governo e empresas normalmente se iniciam pela troca informal de informações, pela prestação de serviços especializados (conferências, consultorias, publicações, etc.), pela organização de cursos e programas de capacitação, especialização, etc. Visto isto, com a percepção dos interesses comuns e estabelecimento de relações de confiança, avança-se para etapas mais evoluídas de cooperação como o intercâmbio de pesquisadores, a difusão e a transferência de tecnologias, através do desenvolvimento de projetos e pesquisas conjuntos entre diferentes organizações no âmbito de Sistemas de Inovação, locais e nacionais, e envolvendo diferentes países (SBRAGIA, 2006; SCHMOCH, 1999; LUNDVALL, 1985; SUTZ, 1997; ETZKOWITZ, 2004).

Sbragia (2006) salienta que as parcerias entre empresas, governo, universidades e centros de pesquisa trouxeram para o centro da discussão a gestão da propriedade intelectual e a sua titularidade, bem como as formas de licenciamento da tecnologia quando geradas pela universidade e exploradas pela empresa, entre estas: os contratos através das licenças não exclusivas, sem pagamento de royalties e as licenças exclusivas 
com pagamento de royalties. Um bom resultado de pesquisa não é suficiente para iniciar o processo de sua comercialização, pois é preciso demonstrar a viabilidade de transformá-lo em inovação. Neste sentido, o registro da patente torna-se condição para garantir autonomia no processo de licenciamento, mas é insuficiente para o sucesso da transferência, que pressupõe a absorção do conhecimento gerado na universidade pela empresa e requer o empenho de ambas as partes no processo de comunicação (idem).

Ainda segundo o autor, lidar com esses aspectos é uma das principais funções dos escritórios de transferência de tecnologia, dos parques tecnológicos e das incubadoras onde as empresas se associam a uma universidade. Estas estruturas complexas têm sido criadas na interface entre as universidades, as empresas e o mercado com o intuito de realizar a pesquisa básica, mas com relevância industrial.

O processo de transferência de tecnologia é definido como a troca de tecnologia e de know-how entre parceiros, objetivando aprimorar conhecimento e melhorar a capacidade competitiva dos envolvidos, tendo como foco os resultados da pesquisa científica e os aspectos de licenciamento e comercialização (SCHMOCH, 1999; SBRAGIA, 2006).

O objetivo principal dos escritórios de transferência de tecnologia é acompanhar as várias etapas do processo de desenvolvimento de um projeto com potencial interesse para o setor privado, entre estas: (i) pesquisa e desenvolvimento de invenção ou protótipo de laboratório; (ii) elaboração e obtenção de carta-patente; (iii) negociação e licenciamento; (iv) desenvolvimento da produção e comercialização (SBRAGIA, 2006).

Ressaltam-se ainda as incubadoras de empresas e os parques tecnológicos como arranjos favoráveis à cooperação universidade - governo - empresa. As incubadoras, enquanto espaço físico destinado a abrigar e apoiar micro e pequenas empresas, sobretudo, se de base tecnológica, têm como objetivo desenvolver e comercializar resultados da pesquisa acadêmica. As incubadoras de empresas são consideradas como uma das principais estruturas que estimulam e facilitam a vinculação empresa, governo e universidade, atraindo vários grupos de interesse, entre estes: empresários, empresário-acadêmicos, agentes financeiros e venture capitalists e o governo por meio de suas agências de desenvolvimento (SBRAGIA, 2006). O Quadro 3 a seguir relaciona as principais formas e contextos onde ocorre a cooperação entre universidades e empresas:

\section{Quadro 3: Contextos e formas de cooperação universidade - governo - empresa}

\section{CONTEXTOS E FORMAS DE COOPERAÇÃO}

Relações pessoais informais nas quais a universidade não é envolvida: consultoria; workshops para troca de informações; "spin-offs" acadêmicos nos quais empresas são criadas para oferecer produtos/serviços resultantes de pesquisas realizadas; publicações de resultados de pesquisas;

Relações pessoais formais nas quais são elaborados convênios entre a universidade, governo e a empresa: bolsas de estudo públicas e privadas de apoio à pós-graduação; estágios de estudantes e cursos sanduíche; períodos sabáticos para professores; intercâmbio de pesquisadores; editais das agências de fomento;

Envolvimento de uma instituição de intermediação: "liaison offices" - escritórios de transferência de tecnologia; associações industriais; institutos de pesquisa aplicada; escritórios de colocação de estagiários e trainees nas empresas e em instituições públicas; consultoria institucional; agências de fomento;

Convênios formais sem objetivo definido: convênios guarda-chuvas; patrocínio industrial ou governamental de P\&D em departamentos da universidade; doações e auxílios para pesquisa (pesquisa pública e privada); Convênios formais com objetivos definidos: pesquisa contratada; serviços contratados como desenvolvimento de protótipos, testes, etc.; treinamento de funcionários das empresas; treinamento "on-thejob" para estudantes; projetos ou programas de pesquisa cooperativa; editais das agências de fomento; Criação de estruturas especiais: contratos de associação; consórcios de pesquisa Universidade - Empresa (ou centros de pesquisa cooperativa); incubadoras de empresas; parques tecnológicos; fusões (mergers); agências de desenvolvimento e Sistemas de Inovação.

Fonte: Adaptado de Sbragia (2006). 
Em relação aos arranjos para a transferência de tecnologia, consideram-se ainda as discussões sobre os Sistemas de Inovação, enquanto contexto institucional chave para a colaboração entre universidades, empresas e governo - triple helix -, promovendo a transformação do ensino e da pesquisa tradicional para a ideia de universidade empreendedora e integrando o desenvolvimento econômico e social local e regional (LUNDVALL, 1992; ETZKOWITZ, 2004; ETZKOWITZ; KLOFSTEN, 2005).

A percepção da natureza sistêmica e complexa da inovação contrapõe-se à noção tradicional característica do chamado "modelo linear", o qual estabelecia uma sequência bem definida que se inicia com as atividades de pesquisa básica e desemboca na adoção de novos processos e produtos. Na abordagem sistêmica, a inovação passa a ser considerada como o resultado de trajetórias que são cumulativas e construídas historicamente, de acordo com as especificidades institucionais e padrões de especialização econômica, inerentes a um determinado contexto espacial ou setorial (ROTHWELL, 1995).

A composição dos Sistemas de Inovação é dada por diversas organizações de apoio, entre as quais: universidades e centros de pesquisa, centros de educação tecnológica (CEFET), empresas de consultoria, laboratórios de pesquisa e desenvolvimento (P\&D), agências governamentais de fomento, sistema legal, governos, associações empresariais, agências reguladoras visando à geração, à importação, à adaptação, à difusão e à transferência de inovações.

Nesse sistema o governo tem o papel de promotor, regulador, executor e financiador do desenvolvimento científico, da pesquisa e da capacitação tecnológica. As organizações dos sistemas de inovação participam de programas governamentais de incentivo à cooperação, nos quais a responsabilidade pela implementação recai em geral sobre a universidade. Entre estes programas ressaltam-se: o Fundo Nacional de Desenvolvimento Científico e Tecnológico (FNDCT), gerido pelo Ministério da Ciência e Tecnologia (MCT), que se compõe de 15 fundos setoriais; os instrumentos de incentivo como: Inovar, Progex, Prêmio FINEP de Inovação Tecnológica, e os demais editais das agências de fomento como Conselho Nacional de Desenvolvimento Tecnológico (CNPq), a Financiadora de Estudos e Projetos (FINEP) e as Fundações de Apoio a Pesquisas (FAPs) (MOREIRA et al., 2007).

$\mathrm{Na}$ abordagem do Sistema de Inovação, reconhece-se que a inovação compreende mais do que P\&D; realçando, ainda, o papel das atividades realizadas por pequenas e médias empresas (PMEs), introduzindo uma conotação geopolítica importante, sobretudo, para os países em desenvolvimento e em termos de implementação de políticas públicas (MINTELKA, 1993).

Para Vedovello e Figueiredo (2006), as organizações de apoio aos Sistemas de Inovação são organizadas para promover e facilitar a disseminação de informação, conhecimento e tecnologia de fontes relevantes para as empresas e outras organizações, auxiliando-as a desenvolver suas competências tecnológicas e adotar, produzir e comercializar inovações. Segundo os autores, para os diversos atores inseridos nos Sistemas de Inovação, a geração, transferência e uso da informação, conhecimento e tecnologia constituem uma atividade fundamental, sendo as sinergias estabelecidas entre esses atores cruciais para o alcance dos resultados. Este arranjo explora não somente as ligações estabelecidas entre as organizações de apoio ao Sistema de Inovação e às empresas, mas também àquelas que ocorrem dentro das próprias organizações de apoio. Vedovello (1998) afirma que as ligações estão baseadas no compromisso dos atores envolvidos, por meio de contratos, bem como no pagamento, ou não, de taxas para que tais interações ocorram. Estas, segundo a autora, estão classificadas em três categorias principais:

i. As ligações informais: nas quais as empresas, em suas buscas por soluções técnicas ou tentativas de implementar inovações, estabelecem contatos com informações e conhecimentos, expertise e equipamentos disponíveis nas universidades, institutos de pesquisa e centros de formação, que por sua vez, estabelecem contatos com as empresas e suas competências e necessidades tecnológicas. Para a autora o estabelecimento dessas ligações não implica o estabelecimento de contratos formais, podendo, algumas vezes, pequenas taxas serem cobradas. 
ii. As ligações de recursos humanos: estão relacionadas com o recrutamento, com a melhoria e desenvolvimento de competências de recursos humanos qualificados. Estas ligações ampliam as possibilidades de promoção de educação continuada e tecnológica em áreas de interesse específico das empresas. Por outro lado, grupos de pesquisa ou pesquisadores individuais podem fortalecer suas ligações com empresas, no sentido de aumentar a oferta de posições de trabalho para os seus recursos humanos qualificados, e ampliar a base educacional, ou o seu portfólio de pesquisa.

iii. As ligações formais: estabelecem-se, quando as empresas cientes dos recursos disponíveis nas organizações de apoio ao Sistema de Inovação (universidades, centros de pesquisa, etc.) conhecimento e informação, recursos humanos qualificados e equipamentos - contratam a utilização de um equipamento específico ou projetos de pesquisa conjuntos, para apoiar e complementar seus esforços tecnológicos. Por outro lado, as universidades e centros de pesquisa, após estabelecer familiaridades com o ambiente empresarial e suas competências, podem desejar fazer uso de equipamentos industriais ou oferecer sua expertise científica, ampliando seus portfólios de pesquisa e seus rendimentos financeiros, com o desenvolvimento de contratos de pesquisa ou o desenvolvimento de pesquisa conjunto. Essas ligações pressupõem o estabelecimento de contratos formais entre os parceiros, onde o compromisso e o pagamento de taxas são previamente negociados.

\section{Metodologia da pesquisa}

Na operacionalização deste estudo de caráter exploratório-descritivo e natureza qualitativa utilizou-se o escopo metodológico do estudo de caso. Conforme Triviños (1992), o grande valor dessa técnica é fornecer conhecimento aprofundado de uma realidade delimitada, onde os resultados atingidos podem permitir hipóteses para o encaminhamento de outras pesquisas. No estudo de casos, os instrumentos de coleta de dados podem ser diversificados, dando flexibilidade à análise (YIN, 1994).

Com isto, para a obtenção dos dados, serviu-se de roteiros de entrevista temática, aplicados de forma individual com os gestores e um empresário do Parque de Desenvolvimento Tecnológico (PADETEC) de uma universidade federal. As temáticas abordadas nos roteiros de entrevistas foram estabelecidas a partir das categorias teóricas sobre a cooperação universidade - empresa - governo, refletindo, sobretudo, os objetivos deste estudo. Utilizou-se ainda como fonte de evidência o levantamento e compilação de documentos.

$\mathrm{Na}$ análise qualitativa das informações coletadas foi utilizada a técnica da Análise Temática que se insere no conjunto das técnicas da Análise de Conteúdo (BARDIN, 2004), cujo objetivo é evidenciar os itens de significação a partir da descrição do corpus que foi construído; tendo por base as unidades de codificação recortadas do conteúdo das entrevistas e dos documentos, sendo estas orientadas pelos objetivos desse estudo. Para isto, foram percorridas as diferentes fases de análise: i) transcrição, constituição do corpus e pré-análise; ii) leitura flutuante e a exploração do material com o estabelecimento de categorias e dos itens de significação; iii) tratamento dos dados através da inferência e interpretação; iv) confronto e discussão dos resultados obtidos com a teoria articulada.

Conforme explica Bardin (2004), esse diálogo entendido à luz de categorias e informações contextuais variadas faz emergir a interpretação como elemento intrínseco ao processo de pesquisa. Dessa forma, iniciando com as categorias teóricas, esse processo levou, em um segundo momento, à redefinição das categorias analíticas em torno dos seguintes blocos temáticos, a saber: (i) o empreendedorismo acadêmico: motivações e barreiras; (ii) o empreendedorismo acadêmico: arranjos de colaboração e sistemas de inovação. 


\section{O caso do Parque de Desenvolvimento Tecnológico (PADETEC) da Universidade Federal do Ceará} (UFC)

O Parque de Desenvolvimento Tecnológico (PADETEC) (http://www.padetec.ufc.br) da Universidade Federal do Ceará (UFC) foi criado em 1990 e inaugurado em 5 de junho de 1991, com o propósito principal de ser uma incubadora de empresas de base tecnológica. Hoje, o PADETEC, com 12 anos de fundação, é um dos mais modernos centros de pesquisa do país com importantes laboratórios, tendo já gerado quase 100 (cem) patentes e, inserido no mercado dezenas de pequenas e médias empresas, através do desenvolvimento cooperativo de pesquisas nas mais variadas áreas, destacando-se: química fina, eletrônica, mecânica fina, alimentos, suplementos alimentares, cosméticas, compósitos, fitoterápicos, produtos naturais, energia alternativa, etc. O PADETEC tem como missão contribuir para o desenvolvimento sócioeconômico do Estado do Ceará, através da inovação e da criação de empresas de base tecnológica. Entre os seus objetivos sobressaem-se: (a) estimular a criação de empresas de base tecnológica; (b) apoiar o desenvolvimento de processos modernos e inovadores; (c) incentivar o desenvolvimento de novos produtos; (d) oferecer apoio técnico a pesquisadores; (e) promover a incubação de empresas de base tecnológica; (f) prestar assessoramento a empresas para a criação de produtos inovadores; (g) proporcionar maior integração universidade-empresa; e (h) agenciar transferência de tecnologia.

O PADETEC enquadra-se, portanto, na interseção dos conceitos de universidade empreendedora e empreendedorismo acadêmico, já que se caracteriza como uma estrutura a qual foi fundada dentro da universidade para abrigar empresas de base tecnológica e que tem na cooperação com os pesquisadores da universidade sua base operacional.

\section{Apresentação e análise do caso}

Buscando ressonâncias na literatura articulada na primeira fase deste artigo, expõe-se a seguir a análise final baseada nas categorias empíricoanalíticas definidas durante o processo interpretativo do estudo.

\section{O empreendedorismo acadêmico: motivações e barreiras}

Segundo Sbragia (2006), as motivações para a busca da cooperação entre universidade e empresa dependem de quem toma a iniciativa. Para o gestor do PADETEC e corroborando às afirmativas de Etzkowitz (2004), Etzkowitz e Klofsten (2005), Garnica, Ferreira-Júnior e Fonseca (2005), não somente a universidade é empreendedora, mas, sobretudo, as pessoas ligadas às universidades exercem o empreendedorismo acadêmico, ao tomarem a iniciativa participando de editais e programas de incentivo à parceria:

[...] a universidade é empreendedora, mas, principalmente, as pessoas, os pesquisadores da universidade que participam dos editais da Finep, CNPq, Petrobrás, BNDES, etc., são empreendedores. Temos um volume grande de recursos alocados através da iniciativa dos pesquisadores da universidade que se associam ao Padetec. Por exemplo, na área do empreendedorismo, assim como em outras áreas, o Padetec está com várias teses de mestrado e doutorado da universidade sendo aqui desenvolvidas, com a única exigência que estas sejam voltadas para o mercado. Não aceitamos teses exclusivamente acadêmicas. Se os alunos têm teses cujo resultado final é a criação de uma empresa ou o lançamento de um produto no mercado, o Padetec dará todo o apoio. Atualmente, temos 30 (trinta) bolsistas trabalhando suas teses aqui (Trecho da entrevista com o Gestor do Padetec).

Pelo lado da empresa, temas evidenciaram que as motivações para empreender no contexto da interação universidade - empresa - governo estão baseadas no reconhecimento do papel concedido à inovação, na ideia de que a tecnologia se tornou a mercadoria global para a competitividade e da necessidade de um posicionamento frente às demandas em prol do desenvolvimento (FREEMAN, 1987; LUNDVALL, 1985; SBRAGIA, 2006).

[...] Necessitamos primeiramente não depender da tecnologia alheia e em segundo lugar devemos estar à frente da concorrência, desta forma e com o intuito de criar ou renovar tecnologia própria, já 
que uma empresa necessita estar sempre inovando. Desta forma, eu nunca esqueço que o nosso DNA é a universidade (Trecho da entrevista com o Empresário).

Segundo a literatura analisada, a busca por novos recursos humanos, financeiros e tecnológicos é uma importante motivação para que as universidades e também para as empresas (SBRAGIA, 2006; LIMA; FIALHO, 2001). Esta assertiva foi corroborada pelo gestor do PADETEC e pelo empresário:

O Padetec é visto pelas empresas como centro radiador de tecnologia e a universidade que está associada ao Padetec como fonte de mão-de-obra qualificada (Trecho da entrevista do Gestor).

[...] estamos sempre propondo convênios, como o de subvenção econômica da Finep, promovendo certificações e articulações com instituições e centros de pesquisa avançada, em busca de novas ideias e inovações, bem como buscando pessoas - estudantes, trainees, mestres e doutores para trabalharem em nossa empresa (Trecho da entrevista do Empresário).

Segundo Fritsch e Schwirten (1999), além de permitir uma aproximação com a realidade técnica, econômica e social, a participação das universidades e centros de pesquisa nestas relações está vinculada à geração e ao desenvolvimento de novas ideias para empresas inovadoras. Neste sentido, os temas analisados evidenciaram novas convergências de visões:

Na área de transferência de tecnologia, o empresário de fora, quando vem aqui, ele está atrás do conhecimento e nós fazemos esta ponte. Nós pegamos a tecnologia da universidade, desenvolvemos nos nossos laboratórios e passamos para a empresa. Mas o empresário local que está querendo empreender, ele vê o Padetec como uma ponte para alavancar o seu negócio (Trechos da entrevista do Gestor).

Eu devo parte do que eu sou à universidade, primeiramente por que a universidade tem esta fantástica capacidade de possibilitar a mobilidade social através da transmissão e, sobretudo, da aplicação de conhecimentos visando à geração de negócios [...] assim eu tive a coragem de voltar à universidade em busca de ideias com potencial para serem transformadas em produtos inovadores. A nossa empresa há 10 anos que funciona baseada em 100\% de conhecimento acadêmico, associado à vontade de empreender (Trecho da entrevista do Empresário).

As evidências emersas, além de confirmarem, segundo Lima e Fialho (2001), que, em regra, são as empresas que buscam as universidades para firmarem parcerias de cooperação; por outro lado, a descrição do bloco temático abaixo colocado, denota formas diferenciadas de motivações para a aproximação da universidade com a empresa e vice- versa, através da iniciativa interinstitucional:

O Padetec, através do Sebrae, tem um programa de formação específica para a criação de pequenas empresas de base tecnológica, visando montar empresas inovadoras, mas, normalmente, quem nos procura é o pequeno empresário, tanto gente do Ceará como de fora do Ceará, quando querem desenvolver negócios inovadores. Estudantes também procuram o Padetec no sentido de viabilizar sua empresa (Trecho da entrevista do Gestor).

Conforme evidenciado nos blocos temáticos anteriores, a existência de uma incubadora de empresa atrai para sua órbita de interesse diferentes grupos, entre os quais: empresários, estudantes-empresários-acadêmicos, venture capitalists e o governo por meio de suas agências de desenvolvimento (SBRAGIA, 2006). Corroborando, itens significativos da entrevista do empresário, salientaram a formação de redes de relacionamento e teias de conhecimento necessárias à iniciativa empreendedora que a relação com a universidade facilita (ETZKOWITZ, 2004; ETZKOWITZ; KLOFSTEN, 2005):

A universidade possibilita fazer teias de conhecimentos e teias de relacionamentos visando à aplicação e gerenciamento desses conhecimentos; ou seja, a universidade te possibilita empreender e inovar gerenciar recursos humanos, financeiros e tecnológicos ao transformar uma ideia em produtos e serviços (Trecho da entrevista com o Empresário). 
Segundo o gestor, o PADETEC nasceu em 1992 com o objetivo principal de ser uma incubadora de empresas. Nesta época, a primeira grande barreira foi a falta de compreensão, por parte da própria universidade, do significado do trabalho do Parque pois, a ideia de empresa privada dentro da universidade era muito difícil de ser assimilada pela academia. Estes temas extraídos da análise corroboram a afirmativa de Sbragia (2006) sobre o clima de desconfiança mútua, diferença de linguagem, choque de cultura e não alinhamento de ideias entre as partes.

O Padetec foi inaugurado quase escondido, apesar do apoio da universidade, que não queria a divulgação, pois muitos achavam que isso seria o início da privatização da universidade (Trechos da entrevista do Gestor).

O incentivo ao estabelecimento desse vínculo foi se intensificando, sobretudo, através da implementação de políticas públicas, objetivando garantir a excelência em áreas temáticas consideradas estratégicas em função do seu potencial de contribuição para o crescimento da economia, melhorias das condições de vida da população, para competitividade das empresas, das regiões e das nações no contexto local e global (LASTRES et al., 2005; FRITSCH; SCHWIRTEN, 1999). Nas palavras do Gestor:

Hoje, com a nova Lei da Inovação Tecnológica e com a filosofia de que a inovação tecnológica passou a ter importância no cenário internacional, mais ainda do que outros setores, como a mercadoria do futuro que é o conhecimento, as coisas mudaram muito.

Além das diferenças culturais, outras barreiras à cooperação universidade e empresa foram evidenciadas em dois blocos temáticos relativas à questão sobre quem financiará esta relação e quais as formas de contratação de pesquisadores que atuarão no PADETEC. Segundo o Gestor:

A universidade não poderia financiar. Pelo contrário, nós pagamos a universidade aluguel, etc. As empresas nascentes são obrigadas a pagar uma taxa de administração, de ocupação, que equivale ao aluguel e ao condomínio para ter todos os serviços e direitos, mas esta taxa é insignificante para a manutenção do Padetec. Por outro lado, o Padetec não pode criar uma empresa e dá uma carga tributária muito forte, caso contrário a empresa não sobrevive. A incubadora de empresa não é autosuficiente o que ela arrecada de aluguel não é suficiente para manter a sua infraestrutura, nós temos que também aportar recursos. Então, para financiar as atividades do Padetec, foi necessário um esforço muito grande da administração para firmar convênios, contratos de prestação de serviços e evidentemente todas estas atividades foi que permitiram que o Padetec tivesse a sustentabilidade que tem hoje.

Em relação às barreiras ligadas aos recursos humanos, os autores salientam que os projetos de cooperação entre universidades e empresas, normalmente se iniciam pela troca informal de informações e pela prestação de serviços especializados (SBRAGIA, 2006). Nas palavras do Gestor:

Outra dificuldade é a de pessoal. O Padetec optou, segundo os modelos de instituições por aí afora, por não ter um corpo físico permanente de pessoal. O que tem os dois lados da moeda. Se avaliarmos a evolução das instituições públicas de pesquisa no Brasil, não ligadas ao ensino, elas têm um período de nascimento, crescimento e depois morte. Cria-se um corpo de pessoal que após vira "funcionário público", desta forma a instituição vai perdendo o dinamismo, à medida que o pessoal vai envelhecendo, trabalham ou não, ganham igualmente os seus salários. Este modelo nós evitamos, tínhamos já exemplos aqui [...] onde está acontecendo este fenômeno. Então nós optamos por um modelo corajoso, arrojado e perigoso no sentido que todo mundo aqui está ligado a um projeto. $O$ projeto acabou, o contratante está desligado do Parque. Isto dá uma vitalidade muito grande à instituição, mas também tem o outro lado da moeda: o fato de não termos um corpo de pessoal permanente. A rotatividade é muito grande e pouca gente com capacitação compromete-se a entrar nesse sistema, desta forma fica difícil de gerenciar o conhecimento, sobretudo a memória. Hoje estamos com oito projetos em andamento e são oito equipes trabalhando aqui. 
Outros trechos temáticos evidenciaram as ações que poderão ser implementadas com o objetivo de intensificar as relações entre as universidades, governos e o sistema de produção e de compreender as distâncias de conhecimento e inovação entre as duas realidades (LUNDVALL, 1985; SUTZ, 1997):

Da parte do governo, políticas públicas necessitam serem efetivadas no sentido de motivar esta aproximação e garantir a efetividade de ações, como, por exemplo, a ampliação da oferta de bolsas e recursos para o desenvolvimento de pesquisas aplicadas, etc. A universidade também deveria se ocupar do marketing científico em prol da aproximação com os sistemas de inovação e produtivo local (Trecho da entrevista do Empresário).

\section{O empreendedorismo acadêmico: arranjos de colaboração e sistemas de inovação}

Segundo Sbragia (2006), escritórios de transferência de tecnologia, parques tecnológicos, incubadoras de empresas são arranjos e estruturas complexas que têm sido criadas na interface entre as universidades, as empresas e o mercado com o intuito de realizar a pesquisa básica, mas com relevância industrial. Neste sentido e conforme temas analisados nos documentos, o PADETEC é uma entidade sem fins lucrativos, criado em 1999 por um conjunto de instituições entre estas: a Universidade Federal do Ceará (UFC), o Banco do Nordeste (BNB), o Serviço Brasileiro de Apoio às Micro e Pequenas Empresas (SEBRAE), o Centro de Treinamento e Desenvolvimento da UFC (CETREDE) e o Governo do Estado do Ceará, com a finalidade de ser um centro de pesquisa e negócios ao mesmo tempo, visando à transferência do conhecimento gerado na universidade para o sistema produtivo, através do processo de incubação de empresas que é considerado o mais eficiente hoje para fazer esta interligação. Segundo a entrevista do gestor, a universidade faz parte do nosso conselho consultivo, mas o PADETEC não faz parte do organograma da universidade.

Nós temos autonomia, sede e CNPJ próprios; contudo, estamos dentro do campus da UFC e pagamos aluguel por isso. Desta forma existe uma relação formal e informal com a universidade. Na época em que o Padetec foi criado, inclusive por inspiração da própria UFC (que cedeu o terreno e o prédio), não existia nenhum instrumento le gal que permitisse à universidade criar uma instituição com este tipo de autonomia e não adiantava, para efeito de organização funcional e administrativa, criar uma instituição ligada a organograma da universidade para executar este tipo e atividade. Neste sentido o Padetec tem um arranjo especial e, para todos os efeitos, ele é a incubadora de empresas da UFC (Trechos da entrevista do Gestor).

Do bloco temático acima descrito, vale ressaltar que, apesar das barreiras enfrentadas, a Universidade Federal do Ceará juntamente com outras organizações empresariais e instituições governamentais tomou a iniciativa para fundar uma estrutura complexa - o PADETEC - de suporte para a criação de empresas de base tecnológica. Neste sentido e segundo Etzkowitz (2004) e Etzkowitz e Klofsten (2005), a UFC se enquadra no conceito de universidade empreendedora.

Em relação ao Escritório de Transferência de Tecnologia, o gestor do PADETEC afirma que este é oficialmente o organismo da universidade, em geral ligado as pró-reitorias de extensão, que deveria exercer o papel de transferência de tecnologia. Contudo, no caso sob estudo, o PADETEC está exercendo esse papel, já tendo gerido a transferência de tecnologia para várias empresas brasileiras e do exterior. Este achado encontra suporte na discussão teórica sobre a necessidade da criação de estruturas complexas de apoio à formação de empresas na universidade visando promover a cooperação (ETZKOWITZ; KLOFSTEN, 2005)

Segundo Sbragia (2006), um bom resultado de pesquisa não é suficiente para iniciar o processo de sua comercialização, sendo necessário demonstrar a viabilidade de transformá-lo em inovação. Desta forma, a propriedade intelectual, os registros de patentes, bem como as formas de licenciamento da tecnologia devem ser geridos no contexto das relações universidade, governo e empresa. Conforme o gestor do PADETEC, o licenciamento para a transferência de tecnologias ocorre através de contratos realizados pelo Escritório de Propriedade Intelectual do Parque, onde os inventores registram suas patentes e marcas. Contudo, temas extraídos da entrevista com o empresário trazem à tona diferenças culturais, colocando em evidência distintas visões e objetivos que terminam condicionando diferentes formas de licenciamento: 
A transferência do conhecimento da universidade para a empresa não funciona no sentido da "sociedade" entre universidade e empresa. Por conta das diferentes culturas, existem "mesquinharias" por parte daquele que cria o conhecimento (pesquisador) em confronto àquele que aplica e comercializa a ideia (o empreendedor). Este último é visto pelo primeiro como "ignorante". No entanto, conhecimento sem prática é inútil, conhecimento precisa ser aplicado em produtos e comercializado no mercado. Desta forma, uma forma de licenciamento boa para todos seria o pagamento de royalties (Trecho da entrevista do Empresário ).

Por outro lado e apesar de o registro da patente ser condição para garantir autonomia no processo de licenciamento, é insuficiente para o sucesso da transferência, que pressupõe a absorção do conhecimento gerado na universidade pela empresa e requer o empenho de ambas as partes no processo de comunicação (SBRAGIA, 2006), nas palavras do empresário:

A questão da transferência do conhecimento deverá ser gerenciada também dentro da própria empresa através de ações, no sentido de formar grupos e equipes de pesquisadores com rodízio de funções e com a capacidade para compartilhar seus conhecimentos individuais e transferi-los para o coletivo. A empresa nesse sentido necessita criar valores e regras para uma cultura onde o conhecimento seja compartilhado e formalizado (Trecho da entrevista do Empresário ).

Baseados no reconhecimento de que a inovação é um processo histórico, interativo e cumulativo, trechos da entrevista do empresário e dos gestores salientaram temas de conteúdo sobre a formação de um Sistema de Inovação envolvendo a interação em triple helix - universidade, empresa e governo - denotando etapas já avançadas nas relações cooperativas locais (LUNDVALL, 1985; VEDOVELLO; FIGUEIREDO, 2006; ETZKOWITZ; KLOFSTEN, 2005):

Temos que fazer interagir conhecimento com a vontade de fazer, de empreender: quem tem o conhecimento é a universidade, quem tem a vontade de fazer é a empresa, desta forma deveremos encontrar uma intermediação, pois esta aproximação é um processo político: como nós Estado, como nós universidade, como nós empresa tomamos a iniciativa e a coragem de fazer, tem que ter coragem e, sobretudo, articulação política. Neste sentido, o Padetec é uma instituição que está na fronteira entre os principais atores desse campo político: empresa, governo e universidade (Trecho da entrevista do Empresário).

Para o gestor do PADETEC, existe um sistema embrionário de inovação aqui no Ceará espalhado por várias instituições. Está na UFC, no próprio PATEDEC, na Empresa Brasileira de Pesquisa Agropecuária (EMBRAPA), na Universidade Estadual do Ceará (UECE), nas universidades em geral. A Fundação Cearense de Apoio ao Desenvolvimento Científico e Tecnológico (FUNCAP) está exercendo o papel de coordenador, junto à Secretaria de Ciência e Tecnologia do Governo do Ceará (SECITECE) de apoio ao Sistema Local de Inovação.

O bloco temático abaixo descrito corrobora as colocações teóricas, segundo Lundvall (1992) e Mintelka (1993), sobre a Política de Inovação e o reconhecimento do papel das atividades realizadas por pequenas e médias empresas (PMEs) na composição dos Sistemas de Inovação:

[...] o lançamento do edital PAPPE liderado aqui no estado pela Funcap visando à subvenção de pequenas empresas inovadoras, é um esforço do estado do Ceará, no sentido de implantar o Sistema de Inovação dentro das empresas, que é onde ele acontece. Não adianta querer fazer inovação dentro da universidade. É nela que se desenvolve o conhecimento, mas a inovação, representada em produtos e processos novos, não pode sair da universidade. Se sair, está errado, tem que sair das empresas e é dentro da pequena empresa que sai $75 \%$ da inovação, é lá onde deve acontecer realmente a inovação (Trecho da entrevista do Gestor).

Em termos de políticas públicas governamentais de apoio à cooperação, trechos da entrevista do gestor do PADETEC evidenciam que, ao contrário do que ocorre nos países mais avançados, o Brasil está com a balança 
invertida, no sentido que o governo investe $75 \%$ em inovação e tecnologia e as empresas apenas $25 \%$. Temas extraídos do corpus analítico sinalizaram mudanças de percepções e comportamento promovidas, sobretudo, após a Lei da Inovação, entre estas:

[...] a mudança de comportamento, em relação à inovação no Brasil e no Ceará, está no fato que atualmente os governos disponibilizam recursos a fundo perdido, a partir dos editais, para as empresas desenvolverem inovações. Anteriormente, isto era proibido.

[...] A implementação do fundo "Criatec" pelo BNDES, do qual o Padetec é um dos agentes. Para acessar este fundo não precisa nem ter uma empresa, basta ter uma ideia [...] Se esta sua ideia for considerada boa, o BNDES financia, não com recursos, mas como sócio [...] no Brasil nunca se teve capital de risco, mas para desenvolver empresas de base tecnológica precisa de capital de risco. Agora, pela primeira vez, temos este tipo de capital através do fundo Criatec. $O$ terceiro escritório criado no Brasil foi aqui no Padetec. O BNDES colocou 20 milhões e o Banco do Nordeste colocou mais 20 milhões, totalizando 40 milhões para financiar empresas, ou melhor, ideias de empresa inovadora.

\section{Considerações finais}

Parece claro que tanto as universidades como o governo quanto as empresas se beneficiam de cooperações mútuas. Por outro lado, construir significados para expressões como flexibilidade, efetividade, eficiência, internacionalização e competitividade dentro de instituições acadêmicas parece ser ainda um desafio que se iguala à delimitação de políticas públicas apropriadas a este contexto. O ambiente e os diferentes códigos culturais específicos da universidade e do setor privado (mercado e empresas) devem ser considerados nos modelos de transferência de tecnologia e quando apoiados pelo setor governamental. Neste sentido, o presente trabalho situa a discussão e apresenta evidências empíricas deste relacionamento para um caso específico - O Parque de Desenvolvimento Tecnológico (PADETEC) ligado à Universidade Federal do Ceará (UFC), enquanto instituição situada na fronteira dessas relações de cooperação.

Em relação às questões de pesquisa levantadas, foi possível perceber que a cooperação entre universidades, governo e empresas ocorre de maneira que os atores envolvidos percebem as vantagens da interação, embora reconheçam algumas de suas limitações e desafios.

Entre estes, destacam-se as diferentes linguagens e culturas que geram climas de desconfiança, dificultando a compreensão do papel e do significado da atuação de um Parque Tecnológico inserido no contexto da universidade e, ainda: questões operacionais sobre quem financiará a relação entre os entes participantes e aquelas relativas às formas de contratação dos recursos humanos e celebração de convênios de prestação de serviços visando à sustentabilidade do Parque.

No caso estudado releva-se que o incentivo ao estabelecimento dos vínculos cooperativos está se intensificando, sobretudo, após a implementação de políticas públicas através da Lei da Inovação, objetivando garantir a excelência em áreas temáticas consideradas estratégicas em função do seu potencial de contribuição para o crescimento da economia, melhorias das condições de vida da população e para a competitividade das empresas locais.

Contudo e conforme os blocos temáticos articulados, a universidade sob análise, ao fundar uma estrutura complexa na fronteira dessas relações - o PADETEC - parece se colocar como ente empreendedor, mas são, sobretudo, os pesquisadores ligados à universidade que exercem o empreendedorismo acadêmico, ao tomarem a iniciativa, participando de editais e programas de incentivo à parceria divulgados pelo governo e se associando ao PADETEC.

Do ponto de vista do empresário, um conjunto de ações deverá ainda ser implementado, sobretudo, pela parte da universidade no sentido, por exemplo, de se ocupar do marketing científico e em prol da aproximação com os agentes dos sistemas de inovação e produtivo local. 
Porém, de uma forma geral, os resultados da pesquisa indicam que este processo de cooperação universidade, governo e empresa, sob análise, é avaliado de forma positiva, como reflexo da capacidade das empresas de transformarem conhecimento em inovação e esta em competitividade. É exatamente a dimensão da inovatividade a mais percebida como passível de ser impactada por esta interação. Contudo, observa-se que este olhar positivo é permeado por algumas críticas, como por exemplo, aquela relativa à estrutura organizacional da universidade no sentido de facilitar uma maior integração universidade, governo e empresa, sobretudo, no que diz respeito à transferência de tecnologia.

Neste sentido, contratos, arranjos e um Sistema de Inovação local "embrionário", mas em evolução, estão sendo articulados entre as diversas instituições e organizações públicas e privadas locais e nacionais para a consolidação dessa interação e integração. Sobressai-se ainda das análises o reconhecimento do papel das atividades realizadas por pequenas e médias empresas (PMEs) de base tecnológica na composição desse Sistema de Inovação, ao serem consideradas o lócus da inovação, e cuja participação está sendo fomentada através dos editais públicos induzidos que visam sua subvenção econômica, no sentido de inverter a balança dos promotores dos investimentos do governo para estas últimas.

Por fim, ressalta-se que a atuação de uma universidade empreendedora, mas, sobretudo, o empreendedorismo acadêmico dá sinais de existência, mas é preciso ainda percorrer um longo caminho para se consolidar estes conceitos e, em consequência, a complementaridade entre suas respectivas práticas. 


\section{Bibliografia}

AGRAVAL, A.; HENDERSON, R. Putting patents in context: exploring knowledge from MIT. Management Science, v.48, n.1, p.44-60, 2002.

AUDRETSCH, D.B.; STEPHAN, P. E. Company-scientist locational links: the case of biothechnology. American Economic Review, v.86, p. 641-652, 1996

BAINS, W. How academics can make (extra) money out of their science. Journal of Commercial Techonolgy, v.11, n.4, p. 353-363, 2005.

BARDIN, L. Análise do conteúdo. Lisboa: Edições 70, 2004.

COUPE, T. Science is golden: academic R\&D and university patents. Journal of Techonology Trasnfer, v.28, n.1, p.31-46, 2003.

ETZKOWITZ, H. The evolution of the entrepreneurial university. Int J. Technological and Globalization. Vol.1, no. 1, 2004, p. 64-77.

ETZKOWITZ, H. The new visible hand: an assisted linear model of science and innovation policy. Science and public policy. vol.33, no. 5, 2006, p. 310-320.

ETZKOWITZ, H; KLOFSTEN, M. The innovation region: toward a theory of knowledge - based regional development. R\&D Management 35, MA, USA: Blackwell Publishing Ltd, 2005.

FREEMAN, C. Technology policy and economic performance. Lessons from Japan. London: Pinter Publishers, 1987.

FRITSCH, M.; SCHWIRTEN, C. Enterprise-university co-operation and the role of public research institutions in regional innovation systems. Industry and Innovation, v.6, n.1, june, 1999.

GARNICA, L. A.; FERREIRA-JÚNIOR, I.; FONSECA, S. A. Relações empresa-universidade: um estudo exploratório da UNESP no município de Araraquara/SP 2005. In: XXV Encontro Nacional de Engenharia de Produção. Anais do XXV Enegep (CD-Rom), Porto Alegre, 2005.

LASTRES, H., M.M.; CASSIOLATO, J. E.; ARROIO, A. Conhecimento, sistemas de inovação e desenvolvimento. Rio de Janeiro: Editora da UFRJ; Contraponto, 2005.

LIMA, I. A.; FIALHO, F. A. P. A cooperação universidade-empresa como instrumento de desenvolvimento tecnológico. In XXIX Congresso Brasileiro de Ensino de Engenharia. Anais do Cobenge 2001. Porto Alegre: Abenges, 2001. Disponível em: <http://www.pp.ufu.br/Cobenge2001/trabalhos/UUE014.pdf>. Acessado em: 15 de maio de 2008, às 08:54.

LUNDVALL, B. A. Product innovation and user-producer interactions. Aalborg: Aalborg University Press, 1985.

LUNDVALL, B.A. National Systems of Innovation; towards a theory of innovation and interactive learning. London: Pinter Publishers, 1992.

MANCINI, R.F.; LORENZO, H. C. Potencialidades e barreiras à cooperação universidade, empresa e governo: o caso das micro e pequenas empresas do segmento médico - odontológico do município de Araraquara. In: XXVI Encontro Nacional de Engenharia de Produção. Anais do XXVI Enegep (CD-Rom), Fortaleza, 2006.

MANSFIELD, E. Academic research underlying industrial innovations: sources, characteristics, and financing. Review of Economics and Statistics, v.77, p. 55-65, 1995.

MARGINSON, S; CONSIDINE, M. The enterprise university - power, governance and reinvention in Australia. Cambridge University Press, 272p, 2004.

MINTELKA, L. A role for innovation networking in the other two-thirds. Futures, July-Aug. 1993.

MOREIRA, N. V.A.; ALMEIDA, F. A, S. de; COTA, M. F. de M.; SBRAGIA, R. A inovação tecnológica no Brasil: avanços no marco regulatório e a gestão dos fundos setoriais. Revista de Gestão USP, São Paulo, v.14, n. especial, p. 31-44, 2007.

PORTO, G.S. O que discrimina a decisão empresarial de cooperar com a universidade. In: Anais do XII SIMPÓsIO DE GESTÃO DA INOVAÇÃO TECNOLÓGICA, PGT/USP, Salvador, out./2002.

ROTHWELL, R. Industrial, innovation: success, strategy, trends. In: DODGSON, M.; ROTHWELL, R. The handbook of industrial innovation. Cheltenham: Edward Elgar, 1995. 
SBRAGIA, R. (Coord.) Inovação. Como vencer esse desafio empresarial. São Paulo: Clio Editora, 2006.

$\mathrm{SCHMOCH}, \mathrm{U}$. Interaction of Universities and Industrial Enterprises in Germany and the United States - a comparison. Industry and Innovation, v. 6, no. 1, June,1999.

SCHUMPETER, J. A. Capitalismo, Socialismo e Democracia. Rio de Janeiro: Editora Fundo de Cultura S.A., 1961

STREHARSKY, C.J. Creating ethical university-industry partnerships. SRA Journal / Commentary, Vol. XXXV, pp. 23-30, 1993.

SUTZ, J. Innovación y desarollo em América Latina. Caracas: Nueva Sociedad, 1997.

TRIVIÑOS, A. N. S. Introdução à pesquisa em ciências sociais: a pesquisa qualitativa em educação. São Paulo: Atlas, 1992

VEDOVELLO, C. Parques tecnológicos e a interação universidade-indústria: a proximidade geográfica entre os agentes como uma força motora. Estudos de Economia, v.18, n.1, p.61-80, 1998.

VEDOVELLO, C.; FIGUEIREDO, P. N. Capacidade tecnológica industrial e sistema de inovação. Rio de Janeiro: Editora FGV, 2006.

YIN, R. K. Case study research: design and methods. California: Sage, 1994. 